Cómo citar este trabajo: Pons Esteva, A., \& Rullan Salamanca, O. (2020). Islandness as a conditioning factor for the production of tourist space in the Balearic Islands. Boletín de la Asociación de Geógrafos Españoles, 84, 2804, 1-33. https://doi.org/10.21138/bage.2804

\title{
La isleidad como condicionante de la producción del espacio turístico en las Islas Baleares
}

Islandness as a conditioning factor for the production of tourist space in the Balearic Islands

\author{
Antoni Pons Esteva \\ Antoni.pons@uib.cat \\ Onofre Rullan Salamanca \\ orullan@uib.es \\ Departamento de Geografía \\ Universitat de les Illes Balears (España)
}

\section{Resumen}

La isleidad es un concepto que puede ser entendido tanto por sus connotaciones positivas de apertura al exterior como por las negativas de cierre respecto a los territorios de allende mar. En los estudios sobre islas se ha trabajado a partir de ambos enfoques, mientras algunos autores hacen hincapié en la capacidad de atracción de las islas como destinos turísticos, otros se centran en sus dificultades para generar economías de escala que impulsen la actividad económica. El presente trabajo pretende matizar los dos enfoques tomando como ejemplo diferentes estrategias de producción del espacio turístico en las Islas Baleares. En el caso que nos ocupa, la imagen de las islas como paraísos ha impulsado la actividad turística y ha convertido el archipiélago en uno de los principales destinos del mediterráneo español ofreciendo al mercado plazas turísticas en volúmenes equiparables o superiores a los de sus vecinos continentales. Por otro lado, la dificultad 
de generar economías de escala por su falta de conexión con el continente por vía terrestre ha sido uno de los principales factores que ha contribuido a frenar la producción inmobiliaria. Los importantes volúmenes de plazas turísticas regladas y el éxito de las viviendas de uso turístico, en paralelo al menor grado de artificialización de la franja costera y de la también menor proliferación de residencias secundarias son algunos de los efectos constatados de la isleidad.

Palabras clave: turismo; isleidad; Islas Baleares; plazas turísticas; viviendas secundarias.

\begin{abstract}
Islandness is a concept that can be understood as having both positive and negative connotations: on the one hand, in terms of openness to the outside world and on the other, in terms of being closed off to territories across the sea. Studies on islands have used both approaches, with some authors emphasising the attractiveness of islands as tourist destinations and others focusing on the problems in achieving economies of scale that boost the economy. This article attempts to qualify both approaches by using different production strategies for tourist space in the Balearic Islands as a basis. The idea of 'island paradises' has boosted tourism and turned the Balearic Islands into one of the top destinations in the Spanish Mediterranean, creating tourist capacity on a par with or exceeding their continental counterparts. In turn, the difficulty in generating economies of scale on the islands and the lack of ground-based transport links with the mainland have contributed to curbing real estate development. The high volume of regulated tourist capacity and the success of holiday rentals, alongside the lower level of artificial man-made coastal areas and the proliferation of holiday homes, are just some of the effects felt from islandness.
\end{abstract}

Key words: tourism; islandness; Balearic Islands; tourist capacity; holiday homes.

\title{
1 Introducción
}

La urbanización, entendida como simple materialidad física, se convierte en ciudad cuando sobre ella se despliegan las actividades de producción y de reproducción. Entre las primeras, las actividades turísticas han venido a sumarse a las más tradicionales con especial intensidad desde la segunda mitad del siglo XX. Pero las actividades turísticas, además de desarrollarse en zonas urbanas previamente existentes, también han sido creadoras de espacios urbanos de nueva planta, lo que se ha venido en llamar la urbanización turística.

La urbanización turística funciona de manera diferente a la ciudad tradicional ya que en ella el ocio y el descanso convergen la función productiva de la oferta con la reproductiva de la demanda. 
Una función productiva y reproductiva que se ha llevado a cabo a través de diferentes modalidades (hoteles, apartamentos, residencias turísticas...) en función de estrategias empresariales cambiantes y que, en las últimas décadas, se está expandiendo más allá de los espacios urbano-turísticos de nueva planta, se está difundiendo sobre la ciudad tradicional, es el tautológicamente llamado turismo urbano.

Las intensidades y modalidades de turistización suelen ser diferentes en los territorios insulares si los comparamos con los continentales, especialmente por lo que hace referencia a las tasas de urbanización y a las modalidades turísticas que afectan a ambos tipos de regiones. La condición insular estaría en el fondo de estas diferencias al condicionar, incentivando o restringiendo, las diferentes actividades económicas de las islas.

El presente trabajo analiza estas diferentes intensidades y modalidades comparando el archipiélago balear con otras regiones turísticas mediterráneas y Canarias con la finalidad de medir y explicar el porqué de tales divergencias.

\section{Sobre urbanización turística, estrategias de producción y condición insular}

La literatura que ha analizado la urbanización turística es diversa y no siempre proviene de los mismos campos temáticos. Desde la geografía las islas han sido un importante foco de interés, seguramente debido a la seguridad que ofrece su inequívoca delimitación física y la singularidad que les confiere su relativo aislamiento. Desde la economía se ha insistido en las supuestas desventajas competitivas de las economías insulares con respeto a las continentales. Incluso desde la biogeografía, fuera de los objetivos de este trabajo, se ha insistido en la importancia del hecho insular a la hora de explicar la distribución y características de las especies.

Analizamos a continuación el estado de la cuestión en estas discusiones.

\subsection{La urbanización turística}

La actividad turística en el mundo ha experimentado un rápido crecimiento desde mediados del siglo XX y una de las principales consecuencias ha sido la expansión de áreas urbanas directamente vinculadas al fenómeno. Es lo que Mullins (1991) en su momento llamó urbanización turística. Un tipo de urbanización que se define como un proceso mediante el cual son construidas o reformadas ciudades para uso casi exclusivo de ocio, con lo que el tejido urbano se vincula estrechamente a dicha actividad (Mullins, 2003; Qian, Feng, \& Zhu, 2012). El turismo resulta así 
un generador de espacio urbano con la finalidad de producir, vender y consumir servicios y bienes para residentes temporales (Antón Clavé, 1998).

Existen algunos modelos que describen la expansión espaciotemporal de los asentamientos turísticos costeros, como el de Gormsen (1997) que detalla 4 periferias de expansión del turismo costero -tomando Europa como punto de partida- y sobre el que nos hemos apoyado en varios trabajos anteriores. Gormsen describe una primera periferia centrada en las costas del Mar del Norte y del Báltico, una segunda periferia que alcanzó la ribera norte del Mediterráneo, una tercera periferia que se intensifica en el Mare Nostrum llegando a su ribera sur y a los archipiélagos (Butler, 1980; Capdepón, 2016) y una cuarta periferia turística litoral que, en el contexto de la globalización, han consolidado las empresas transnacionales que han creado nueva urbanización turística en zonas principalmente tropicales de América, África o Asia. En esta última fase han coexistido situaciones postfordistas en forma de viajes personalizados con otras fordistas de producción masiva (Vera \& Baños, 2010). No es este el lugar para discutir sobre la validez de teorías difusionistas como la de Gormsen pero debemos aceptar que

(...) el mundo no es un campo de juego nivelado sobre el que la acumulación de capital pudiese jugar a su libre albedrío (Harvey, 2012 [2000], p. 48).

El desarrollo geográfico desigual (Harvey, 2014, p. 149-164), tan vinculado a las innovaciones en los transportes (carruajes, ferrocarriles, navegación marítima, aviación...) y a las posibilidades que ofrecen las distintas regiones ayuda a entender la expansión de las actividades turísticas.

En términos generales y con independencia de su distribución y difusión geográfica, el turismo ha pasado de 278 millones de turistas en 1980 a 1133 millones en 2014 (García, 2017) convirtiéndose en un fenómeno plenamente planetario. Sin embargo, en sus orígenes europeos, la urbanización turística litoral posterior a la II Guerra Mundial, se centró singularmente en el Mediterráneo, donde sus áreas costeras - de la tercera y cuarta periferia de Gormsen- generaron importantes continuos de superficies artificiales. Desde entonces, en el litoral mediterráneo, se ha pasado de un sistema nodal de ciudades portuarias y pequeños asentamientos, a un modelo lineal articulado sobre el frente de mar. Este proceso de artificialización se ha producido simultáneamente al desarrollo de un sistema de infraestructuras de comunicación rápidas paralelas a la costa (Díaz, 2015) y a la construcción y/o ampliación de infraestructuras portuarias y aeroportuarias. En términos de Lefebvre (1973), la ocupación y producción del espacio explican y permiten comprender del desarrollo turístico que ha afectado y afecta, en particular, las costas mediterráneas. 
Existen multitud de ejemplos de estudios que tratan sobre dicha temática: Costa Brava (Emmi \& Santigosa, 1989); costa valenciana (Ezquerra, Moreno, Otero, \& Urbano, 1999; Martí \& Nolasco, 2011; Rico, Olcina, \& Baños, 2014; Obiol \& Pitarch, 2011); litoral andaluz (Villar, 2011; Almeida \& Cortés, 2011); la Manga del Mar Menor (García-Ayllón, 2015; Ibarra, Belmonte, \& Rubio, 2017); Llenguadoc-Rosselló (Marez, 2012); Canarias (González \& Sobral, 2011; Simancas, García, Dorta, \& Falero, 2011); costa portuguesa (Aguilera-Benavente, Botequilha-Leitao, \& Díaz-Varela, 2014); China (Xi, Zhao, Ge, \& Kong, 2014). Algunos de los estudios que abordan el tema se refieren a espacios insulares (Xie, Chandra, \& Gu, 2013) mientras que otros trabajan a escala mundial (Seto, Fragkias, Günerlap, \& Reilly, 2011).

Las Islas Baleares, como el Estado español en general (Blázquez \& Murray, 2010), experimentaron hacia mediados del siglo XX un importante cambio económico directamente relacionado al llamado plan de estabilización y, en el caso que nos ocupa, vinculado a la actividad turística hasta cristalizar en un claro ejemplo de este tipo de procesos y convertirse en uno de los principales destinos del Mediterráneo en términos de número de turistas (Ruggieri, 2011).

Para el archipiélago Rullan (1999) propuso un modelo para la descripción y explicación del desarrollo de la actividad turística sobre la base de tres "booms turísticos", ampliados recientemente a cuatro (Rullan, 2019, p. 43-45). El primer "boom", cronológicamente situado al final de la década de los sesenta y principios de la de los setenta, fue uno de los resultados más directos del plan de estabilización franquista que vinculaba la economía española con la capitalista occidental cuando estaba cuajando la tercera periferia de Gormsen, fue urbanísticamente intensivo y territorialmente concentrado especialmente en torno a la bahía de Palma. El segundo "boom", en la segunda mitad de la década de los ochenta, estuvo vinculado al ingreso de España en la CEE paralelo a la transición de las economías occidentales del fordismo al postfordismo, nacieron las cadenas turísticas transnacionales de origen balear, se extendió la urbanización y los apartamentos turísticos y chalets fueron las modalidades de alojamiento características. El tercer "boom" turístico se inició a mediados de la década de los noventa y se prolongó hasta el estallido de la burbuja en 2007, la entrada en circulación del euro y la irrupción de las políticas neoliberales están en el fondo de esta fase en el contexto de la cuarta periferia gormseniana. Entre las características de esta tercera fase destacan: la incorporación del espacio rural en la expansión inmobiliaria y turística y la adquisición de propiedades por parte de la población centroeuropea. Finalmente, el cuarto boom turístico ha sido la consecuencia la estrategia neoliberal de salida de la crisis financiera y rescate bancario, una estrategia que, entre otros, ha girado su mirada hacia el 
negocio del alquiler y la comercialización de viviendas turísticas a través de plataformas p2p (Rullan, 2019).

En términos económicos, para las Baleares, este proceso ha supuesto su especialización casi exclusiva en turismo: la segunda región de España en número de turistas y la mayor en número de plazas de alojamiento con el 17,75\% de las plazas del Estado español (UNWTO, 2014; INE, 2018). En 2017 en el archipiélago había disponibles 436315 plazas en establecimientos turísticos y el flujo acumulado de turistas alcanzó la cifra de $16341032^{1}$. Un proceso en el que, en poco más de medio siglo, la superficie artificial se ha multiplicado por seis si comparamos las cifras de 1956 con las de 2006 (Pons, 2003; Blázquez, Murray \& Pons, 2008; Pons \& Rullan, 2014b) (Tabla 1).

Tabla 1. Evolución de las coberturas del suelo artificial en las Islas Baleares

\begin{tabular}{|l|c|c|c|c|c|c|c|c|}
\hline \multirow{2}{*}{ ISLAS } & \multicolumn{2}{|c|}{1956} & \multicolumn{2}{c|}{1973} & \multicolumn{2}{c|}{1995} & \multicolumn{2}{c|}{2006} \\
\cline { 2 - 10 } & $\mathrm{Km}^{2}$ & $\%$ & $\mathrm{Km}^{2}$ & $\%$ & $\mathrm{Km}^{2}$ & $\%$ & $\mathrm{Km}^{2}$ & $\%$ \\
\hline Islas Baleares & 56,27 & 1,13 & 125,35 & 2,52 & 270,65 & 5,44 & 309,85 & 6,23 \\
\hline Mallorca & 48,58 & 1,34 & 95,42 & 2,63 & 199,48 & 5,50 & 231,38 & 6,38 \\
\hline Menorca & 6,15 & 0,89 & 16,41 & 2,36 & 33,60 & 4,84 & 36,45 & 5,25 \\
\hline Ibiza & 1,30 & 0,23 & 12,38 & 2,16 & 35,77 & 6,25 & 40,22 & 7,03 \\
\hline Formentera & 0,24 & 0,29 & 1,02 & 1,23 & 1,81 & 2,20 & 1,82 & 2,20 \\
\hline
\end{tabular}

Fuente: Pons \& Rullan (2014b)

La explotación turística, en forma de urbanización y oferta de alojamiento de todo tipo, debe entenderse como uno de los ejemplos de solución o arreglo espacial ante las sucesivas crisis de sobreacumulación capitalista sobre las que ha teorizado David Harvey (2007) y que, habitualmente, se disipan en el espacio-tiempo a través y mediante el llamado circuito secundario de acumulación (Harvey, 1985). Sin embargo la estrategia económica capitalista en ocasiones también fluye desde el circuito secundario de acumulación vinculado a la producción inmobiliaria, al primario, vinculado a la producción turística ahora en forma de comercialización de gran parte del parque residencial vía alquiler turístico (Murray, Yrigoy \& Blázquez, 2017). 
En el proceso de urbanización tan directamente vinculado al turismo, las Islas Baleares muestran un comportamiento diferenciado con respeto a las regiones turísticas del Mediterráneo español con el que comparten contexto político y económico. La primera franja costera de $1 \mathrm{~km}$, en 2006, tan solo estaba artificializada en un $18,42 \%$ frente al $37,6 \%$ de las regiones continentales del Mediterráneo peninsular (Pons \& Rullan, 2014). La tipología de la oferta turística que se asienta sobre estas áreas artificializadas, como veremos, también es diferente, tanto si nos referimos a Baleares como a las Islas Canarias (Simancas \& Mañoso, 2016).

\subsection{Estrategias de producción de los espacios turísticos}

La solución o arreglo espacial implica producir espacio, en el caso que nos ocupa turístico, y, en consecuencia, impulsa la artificialización y sellado del suelo o, en su caso, la reconversión de espacios urbanos ya existentes. Siguiendo a Martí Ciriquián, Nolasco-Cirugeda y Serrano-Estrada (2018) se pueden reconocer dos estrategias básicas de producción en el espacio turístico: el modelo dinámico de rotación con alojamientos hoteleros en estructuras urbanas compactas y el modelo turístico y/o residencial localizado en zonas urbanas más extensivas. Tales estrategias, directamente vinculadas a la tipología de la oferta de alojamiento como productor de espacio urbano, resultan básicas para la comprensión de la geografía urbana de las regiones turísticas (loannides \& Debbage, 1998). Si bien hay consenso en considerar el alojamiento hotelero como clave a la hora de definir los espacios turísticos y la difusión de la actividad turística, el conocido como turismo o alojamiento residencial genera más discusiones.

Autores como Torres (2003) han señalado la contradicción del concepto de turismo residencial recordando que numerosos foros académicos y profesionales apuntan que no debería ser considerado como turismo. Algunos autores como, Femke van Noorloss (2013), explican el concepto como una mezcla de movilidad permanente y temporal, que se convierte en puente entre turismo y migración y entre nomadismo y sedentarismo. Otros prefieren utilizar el término de turismo inmobiliario (Mazón \& Aledo, 2005; Capdepón, 2016) que une dos sectores productivos independientes pero directamente vinculados.

Sea como sea, lo cierto es que en la costa mediterránea el fenómeno de las segundas residencias, entendidas como tipología de turismo residencial tanto para locales como para extranjeros, se encuentra muy vinculado con el turismo de sol y playa (Serrano Martínez, 2003) y ha impulsado importantes procesos de urbanización. El resultado ha sido un importante aumento de las coberturas artificiales (Rullan, 2008) a causa del rápido crecimiento del parque residencial y de la generalización de nuevas tipologías urbanísticas y edificatorias tales como unifamiliares, 
edificaciones aisladas, etc. (Fernández \& Barrado, 2011) mayoritariamente vinculados al turismo residencial de locales y foráneos.

Existen muchos trabajos sobre el turismo residencial o inmobiliario en el litoral mediterráneo peninsular, varios de ellos centrados en la última gran pulsación de crecimiento que ha afectado a la costa valenciana. Capdepón (2016) trata sobre el "Urban Sprawl" alicantino vinculándolo a segundas residencias y turismo. Obiol y Pitarch (2011) se refieren al fortísimo oleaje inmobiliario del litoral valenciano (1998-2008) y señalan como, en lugar de apostar por un modelo profesionalizado de producción turística, el país valenciano ha sido arrastrado por los intereses inmobiliarios donde los promotores urbanísticos han sido realmente los creadores del urbanismo turístico y los municipios del litoral los más afectados. Actualmente, y ante la fase la fase económica que parece vislumbrarse tras la crisis, es previsible un nuevo ciclo inmobiliario expansivo que azote las costas españolas en paralelo a la reconversión de las zonas turísticas ya existentes.

\subsection{La isleidad}

Las islas ofrecen una imagen compleja de clausura y apertura. Son simultáneamente cerradas y abiertas. El mar que las rodea es, a la vez, vía y obstáculo, camino e imposibilidad. Las islas acogen y rechazan a un tiempo. Quizás sea su ambigüedad su característica principal (Julbe, 1983, p. 95).

En la segunda mitad de siglo XX muchas economías insulares se han especializado en turismo y este se ha convertido en su principal fuerza impulsora de urbanización (Judd \& Fanstein, 1999; Judd, 2003). Para analizar la cuestión, los investigadores de las economías insulares han elaborado el concepto de isleidad. ${ }^{2}$

La isleidad es un concepto controvertido que se ha definido de diferentes formas en la literatura nisológica (Baldacchino, 2004). Los conceptos de isleidad e insularidad han sido utilizados indistintamente en la literatura sobre las islas, con definiciones dispares y muchas veces contradictorias, que han sido objeto de debate. La insularidad es un término más antiguo, y se ha utilizado en los últimos siglos principalmente para tratar sobre la cualidad de las islas, así como los efectos del aislamiento en las comunidades vivas y las poblaciones. ${ }^{3}$ El concepto de isleidad, en cambio, es más reciente, se debe a Moles (1982) que la define como una función fenomenológica

2 Illeïtat en catalán, Islandness en inglés, Îléité en francés (Pons, 2016).

3 Según el Diccionario de la Lengua Española. Real Academia Española y el Diccionari de l'Institut d'Estudis Catalans. 
ligada a tres dimensiones: la magnitud de la isla, la distancia de ésta a las tierras continentales y su carácter microcósmico que le confiere la cantidad de variedad que contiene (Barceló, 1997). Baldacchino (2004) apunta que la insularidad se ha usado habitualmente como término negativo, de cierre frente a lo que viene del continente, y este negativismo no ha hecho justicia al tema de los estudios de islas, en cambio, la isleidad es una variable que no determina, sino que perfila y condiciona eventos físicos y sociales en distintas formas. Jackson (2008) también se refiere a las connotaciones negativas del término insularidad, mientras que la isleidad, en cambio, evoca tanto cierre como apertura. Hepburn (2010) relaciona el término más antiguo de insularidad con la acotación física de las islas, y apunta que como consecuencia de la visión negativa que se le ha atribuido, los eruditos sobre islas han adoptado otro concepto que les ayude a estudiar el carácter distintivo de las islas: la isleidad.

Para el desarrollo del presente trabajo, según lo expuesto en los párrafos anteriores, se ha optado por el uso del término isleidad. El término nos permite realizar una aproximación más precisa con respeto a una constatada dualidad de fuerzas que, al unísono, intervienen en las islas: atracción y repulsión. 4

Por lo que se refiere al turismo, existen estudios recientes que constatan claramente la capacidad de las islas como nexos de unión entre la oferta y la demanda turística. Algunos autores hacen especial hincapié en la ventaja competitiva de los destinos turísticos insulares en comparación con las continentales (Baldacchino, 2006; Murray, 2012; Wortman, Donaldson \& Van Westen, 2016; Péron, 2004). Todos ellos, directa o indirectamente, aluden al "mito de la isla" vinculado a la calma, el sedentarismo, el descanso, etc., como un factor de atracción. Incluso se ha llego a afirmar que

(...) las utopías/antiutopías han tendido a localizarse en islas o espacios aislados. Esencial en el planteamiento utópico es segregar un espacio real o imaginario de la totalidad y organizarlo autónomamente según un modelo. El espacio segregado por excelencia es una isla. Las islas son una constante en la escritura de la utopía. Ofrecen un ejemplo de campo aislado y se acercan a la imagen de ambiente experimental protegido de las influencias externas (Julbe, 1983, p. 93).

4 Sin utilizar el término, Ángel Cabo remarcaba como la península ibérica era una "casi isla" en la que se combinaban y coexistían estímulos de relación (con el exterior) y de aislamiento (Cabo, 1973). Es la misma idea que han apuntado algunos geógrafos que han estudiado las islas. 
En contraposición al "mito de la isla", el "mito de la carretera" suele vincularse al nomadismo, al movimiento y a la acción. Recordemos que el turismo, desde el punto de vista de la demanda, es fundamentalmente una huida de la cotidianidad en la que el trabajo y el movimiento diario hacen muy difícil la calma y la relajación. Butler (1993), propone cuatro características principales por las que los turistas se sienten atraídos por las islas: separación física, diferencia cultural, clima y medio ambiente y política autónoma. Sufrauj (2011) apunta que las islas atraen el turismo por ser pequeñas y remotas y lo corrobora con pruebas empíricas. Esta ventaja competitiva combinada con la escasez de otros recursos explotables (Jackson, 2008), ha permitido constatar a otros autores -como Martín de la Rosa (2003), Wilkinson (1997) o Sinclair (1998)- que en las islas el turismo se ha convertido en la principal y casi obligada actividad económica como motor del desarrollo insular.

Pero más allá de los estímulos de atracción turística que pueda generar el "mito de la isla", la literatura geoeconómica muy a menudo ha considerado la condición isleña como una dificultad para la integración de las economías insulares en estructuras económicas de escala superior. Habitualmente se atribuye esta desventaja al incremento de los costes de transporte (Bjarnason, 2010). Esta literatura entiende la isleidad únicamente como una barrera a la libre circulación y al comercio atribuible al aislamiento que dificulta la conectividad e integración con las economías continentales. Desde esta perspectiva en las islas siempre será necesario un viaje extra y el cambio de un modo de transporte a otro, esto implica que una isla nunca pueda competir en igualdad de condiciones con sus vecinos continentales ya que los costes en una isla siempre tenderán a ser superiores a los de las áreas continentales cercanas (Royle, 1989). El tamaño de las poblaciones insulares, menor que la de los continentes y, por regla general, mayor en las islas grandes que en las más pequeñas, influye también en el consumo que, al verse restringido por esta circunstancia, será menos apetecible para las empresas (Barceló, 1985). La confluencia de todos estos condicionantes implica, desde este enfoque, una mayor dificultad de las islas para generar economías de escala (Pintado \& Fernández, 2010).

Es debido a razones como esta de eficiencia económica que las islas presentan indicadores menores de presión artificializadora sobre su suelo como ya se ha estudiado en otras publicaciones (Pons \& Rullan, 2014; Fernández \& Barrado, 2011).

\section{Hipótesis, objetivos, metodología y fuentes}

La pregunta que nos planteamos responder en este trabajo pretende aclarar si, además de las diferenciales tasas de urbanización del litoral ya conocidas y constatadas, también se da un 
comportamiento diferenciado en cuanto a las tipologías de alojamiento en las regiones insulares respeto a las peninsulares. Lo que se pretende es estudiar las diferentes estrategias de producción del espacio turístico -comparando las Islas Baleares y la costa mediterránea peninsular- con el fin de comprobar si la condición insular ha influido también en las tipologías de alojamiento que han colmatado la urbanización balear.

Si la isleidad condiciona como factor de atracción y, a la vez, de repulsión, se trataría de ver si en las islas, en términos comparables con el continente, el turismo hotelero se habría visto favorecido/atraído y el residencial dificultado/repelido. No únicamente como resultado de determinadas políticas públicas - que pueden haber acompañado la tendencia más general- sino como condicionante geoeconómico de primer orden. La intensidad del uso hotelero favorecido combinado con la extensividad del uso residencial dificultado -como estrategia empresarial de acumulación- explicaría la menor tasa de urbanización costera de los litorales insulares.

Para confirmar la hipótesis nos planteamos analizar y comparar las diferentes regiones más turísticas españolas tanto insulares como continentales: Baleares, Canarias y la franja litoral mediterránea de la Península Ibérica. Un análisis que se concreta en los siguientes objetivos:

i. Analizar las plazas en alojamientos turísticos de estas regiones como indicador de la estrategia relacionada con los modelos dinámicos de rotación.

ii. Analizar las viviendas secundarias de estos ámbitos como indicador de la estrategia de turismo residencial.

iii. Analizar las coberturas del suelo, para comprobar el grado de artificialización que implican las diferentes estrategias de producción del espacio turístico.

Los indicadores seleccionados deben permitir confirmar la hipótesis planteada, es decir, que es la isleidad, con su doble efecto, la principal causante del comportamiento insular diferenciado, aunque es posible que existan otros factores explicativos. Para analizar estos últimos se ha incorporado en el trabajo un apartado específico donde se evalúan de forma cualitativa y a partir de la bibliografía existente, la posible influencia de otros factores como las políticas territoriales.

Todas las regiones analizadas corresponden a la costa mediterránea excepto Canarias que, en una posición subtropical y sin estacionalidad, se diferencia del resto de destinos. En cualquier caso a lo que se aspira es al estudio comparado entre diferentes destinos en aras de una mayor 
comprensión de los procesos y dinámicas turísticas para contrastar semejanzas y diferencias en estos espacios. 5

En el presente estudio se han utilizado diferentes niveles de resolución vinculados a unidades administrativas o estadísticas: NUTS-2 o Comunidades Autónomas, NUTS-3 o provincias y municipios. Los resultados aportados corresponden a los municipios costeros de las provincias de Gerona, Barcelona, Tarragona, Castellón, Valencia, Alicante, Murcia, Málaga, Granada, Almería, Islas Baleares, Santa Cruz de Tenerife y Las Palmas de Gran Canaria.

En cuanto a los datos utilizados, se trabaja con cifras de plazas en alojamientos turísticos y segundas residencias. Los datos de plazas turísticas, correspondientes al año 2015, se han obtenido a partir de la consulta de los portales estadísticos de las Comunidades Autónomas. ${ }^{6}$ Para las segundas residencias se ha utilizado el censo de población y viviendas del 2011 (INE).

Con el fin de determinar los efectos territoriales de los diferentes procesos turísticos también se ha utilizado la cartografía de coberturas del suelo del Corine Land Cover (2012) para analizar la superficie artificializada de la franja del primer kilómetro de costa.

Los datos de plazas turísticas, viviendas secundarias y superficies artificiales se han referenciado sobre cartografía de los municipios mediante el uso de software SIG. Inicialmente se recogieron los datos de plazas turísticas y residencias secundarias de los municipios de la costa mediterránea española y con ello se elaboró una tabla. Posteriormente se confeccionó una capa cartográfica de la costa de cada uno de los municipios, así se vinculó la tabla inicial con la tabla de atributos de la capa. A partir de esta cartografía se han podido explotar los datos y realizar los mapas y gráficos que ilustran los siguientes apartados, permitiendo un análisis más preciso de los fenómenos objeto de estudio.

Para facilitar la tarea de comparación, además de los datos de volúmenes totales de plazas turísticas, viviendas secundarias y superficies artificiales, también se aportan valores relativos respecto de la superficie de la franja del primer $\mathrm{Km}$ de costa con el objetivo de obtener una percepción más clara del grado de presión que recibe la franja litoral. Para ello, se realizó un

5 Otros estudios ya han desarrollado la metodología comparada. En algunas ocasiones se comparan destinos dentro de una misma región; Martí-Ciriquián, Nolasco-Cirugeda y Serrano- Estrada (2018) comparan tres zonas turísticas en la Costa Blanca (Benidorm, Denia y Torrevieja) con modelos diferentes. En otros estudios se apuesta para comprar regiones muy alejadas, como es el caso de Fernández y Barrado (2011), que comparan la España mediterránea, Costa Azul y Florida.

6 Ver bibliografía: Instituto de Estadística y Cartografía, Portal estadístico de la Región de Murcia, Portal estadístic de la Generalitat Valenciana, Institut Estadístic de Catalunya (IDESCAT), IBESTAT e ISTAC (n.d.). 
"buffer" de $1 \mathrm{Km}$ a partir de la línea de costa y se calcularon los datos relativos, según la superficie del buffer en cada municipio.

\section{Resultados}

Los resultados obtenidos se presentan en tres diferentes subapartados en los que se trata sobre turismo reglado y no reglado (4.1), artificialización del suelo (4.2) y otros posibles factores explicativos (4.3)

\subsection{Sobre plazas turísticas y residencias secundarias}

Una primera aproximación a los datos más generales permite constatar como los municipios costeros de las islas españolas presentan volúmenes de plazas turísticas superiores a los de los peninsulares: 820100 plazas turísticas regladas frente a las 759877 de la península (Figura 1). En términos relativos (plazas turísticas $/ \mathrm{Km}^{2}$ de la franja del primer $\mathrm{Km}$ del litoral) la presión es relativamente similar, en el continente se alcanzan las 504 plazas $/ \mathrm{Km}^{2}$ y en Baleares y Canarias, conjuntamente, 422 plazas $/ \mathrm{Km}^{2}$. Estas diferencias entre las cifras absolutas y relativas se explican por un dato que habitualmente pasa desapercibido: las islas tienen más superficie costera que el continente, $1.942 \mathrm{~km}^{2}$ en la franja de $1 \mathrm{Km}$ de costa en Baleares y Canarias conjuntamente frente a los $1505 \mathrm{Km}^{2}$ de las provincias mediterráneas peninsulares. En cualquier caso la provincia de las Islas Baleares (403.445 camas) supera en densidad a la costa española mediterránea (518 frente a 504 plazas $/ \mathrm{Km}^{2}$ ), son las cifras algo menores de las dos provincias canarias lo que provoca que la densidad media peninsular sea algo mayor a la insular.

En la costa peninsular mediterránea, la provincia con mayor volumen de plazas turísticas era Alicante con 180329 plazas, una cifra muy por debajo de las provincias insulares, pero que implicaban una densidad de 897 plazas $/ \mathrm{Km}^{2}$ de la franja del primer $\mathrm{Km}$ de costa. El caso se explica por el enorme peso estadístico de la concentración de Benidorm en una provincia de apenas $225 \mathrm{~km}$ de costa.

Sin embargo, si en lugar de plazas turísticas regladas se analizan las cifras de residencias secundarias se constata la clara supremacía de los municipios continentales frente a los insulares. En los municipios costeros continentales las viviendas secundarias alcanzaban la cifra de 1077 520, mientras que en Baleares y Canarias conjuntamente apenas llegaban a las 188390. Si se utilizan los valores relativos referidos a la superficie de la franja costera del primer $1 \mathrm{Km}$, las densidades también son muy superiores en los municipios continentales en comparación con los insulares: 715 frente a 96 viviendas secundarias $/ \mathrm{Km}^{2}$. 
Figura 1. Plazas turísticas (2015) y residencias secundarias (2011) en los municipios costeros. Costa mediterránea peninsular, Baleares y Canarias
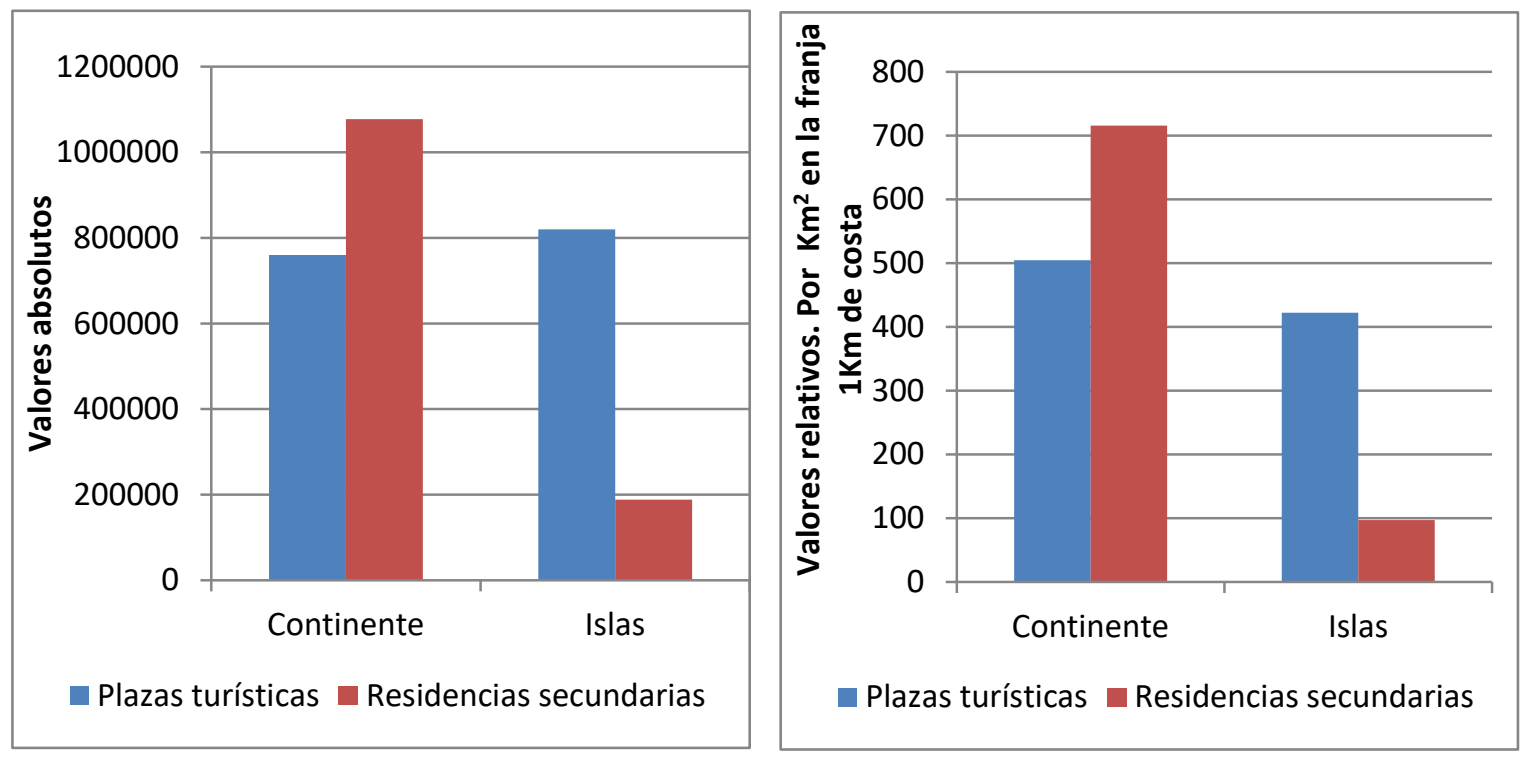

Fuente: INE y portales estadísticos de las Comunidades Autónomas

En los municipios costeros de las Islas Baleares, según datos del censo de 2011, se contabilizaban 79080 viviendas secundarias, cifra muy inferior a los valores de las provincias peninsulares: Alicante (270 545), Málaga (145 065), Valencia (130 470), Tarragona (112 085) o Girona (107 005). En las Islas Canarias la cifra de viviendas secundarias era de 65845 en Santa Cruz de Tenerife y 43465 en las Palmas. En cuanto a las densidades en la franja del primer kilómetro de costa, las Islas Baleares alcanzaban las 101 viviendas $/ \mathrm{Km}^{2}$, cifra similar a la provincia de Santa Cruz de Tenerife (122 viviendas $/ \mathrm{Km}^{2}$ ), pero muy lejos de las cifras de las provincias continentales como las de Alicante (1346 viviendas $/ \mathrm{km}^{2}$ ) o Valencia (1153 viviendas $/ \mathrm{km}^{2}$ ).

Si tomamos como unidad espacial de análisis los municipios costeros del litoral balear y del mediterráneo peninsular los resultados también nos dan una clara diferencia de comportamiento. En los municipios baleares los valores de plazas turísticas son relativamente similares a los continentales, mientras que las viviendas secundarias son claramente inferiores. En la figura 2 se representan los datos de las dos variables de estudio mediante un diagrama de dispersión para los municipios de la costa balear y mediterránea peninsular, y se comprueba como los municipios del archipiélago quedan todos por debajo de la diagonal que se dibuja, lo que indica que el peso de las plazas turísticas es mayor que el peso de las viviendas secundarias. En cuanto a plazas turísticas, el municipio mallorquín de Calvià (58 521 plazas) compite con Benidorm (62 918 plazas) y Barcelona (72946 plazas). Por su parte, las viviendas secundarias son inferiores en los 
municipios del archipiélago en comparación con los continentales, tanto si se mira en valores absolutos como si se analiza la densidad.

Figura 2. Plazas turísticas (2015) y residencias secundarias (2011) en los municipios costeros. Costa mediterránea de la península y Baleares

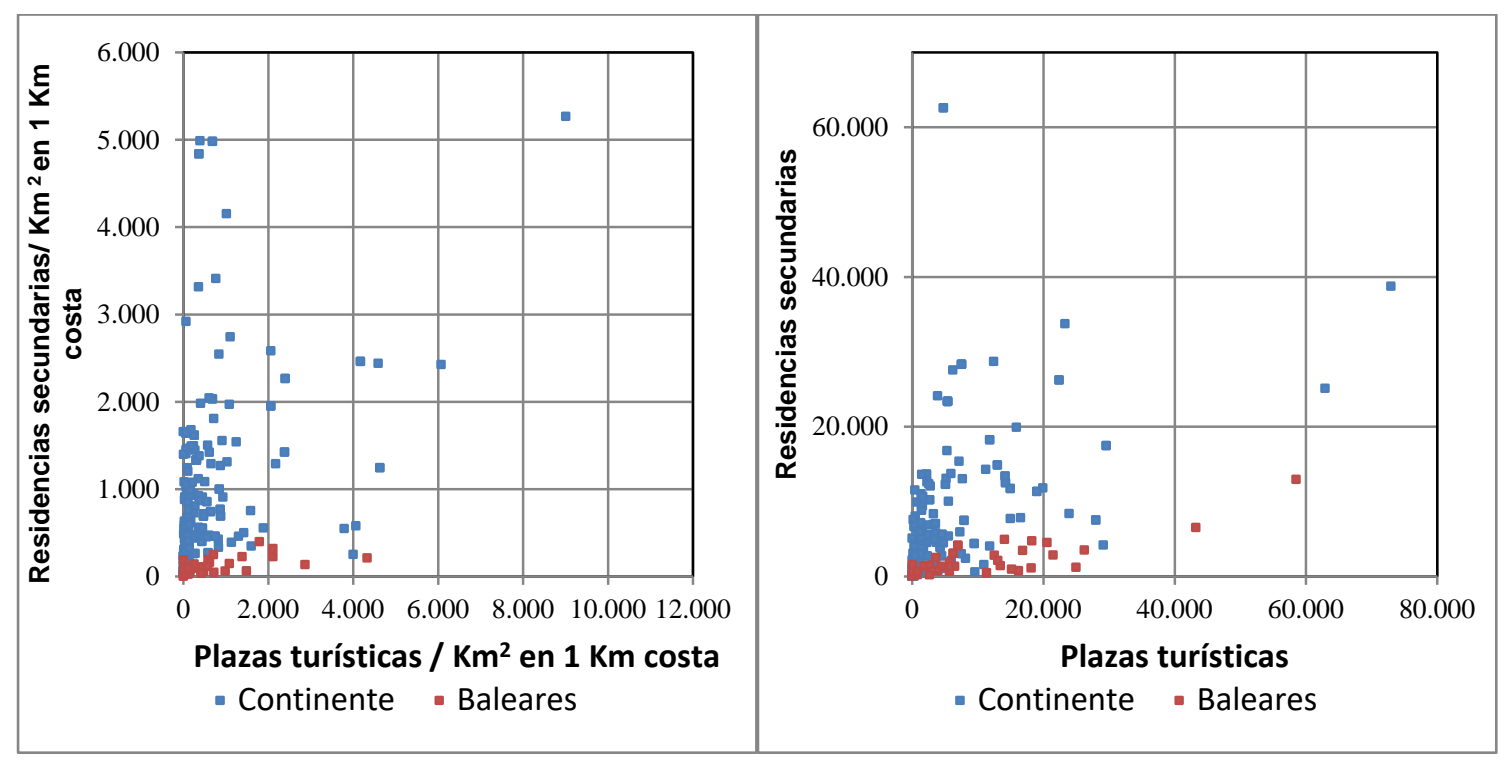

Fuente: INE y portales estadísticos de las Comunidades Autónomas

Si fijamos nuestra atención en los datos por islas, los resultados revelan un mayor peso de las dos variables analizadas en las islas mayores (Tabla 2 y Figura 3). Mallorca, Gran Canaria y Tenerife, como era de esperar por su mayor tamaño, tienen mayores volúmenes de plazas turísticas y viviendas secundarias en valores absolutos, pero tienen también unas mayores densidades referidas a la franja del primer Km de costa. El caso de Ibiza, con valores superiores a los que le corresponderían por su tamaño, debe explicarse a la luz de su singular desarrollo turístico (Blázquez, 2006). Las islas más grandes y mejor conectadas con el continente, las más continentalizadas y con menor grado de isleidad, son también las que reflejan valores más elevados (Pons \& Rullan, 2014) en ambas variables. 
Tabla 2. Plazas turísticas (2015) y residencias secundarias (2011) para municipios costeros. Islas de Baleares y Canarias ordenadas por densidad de plazas $/ \mathrm{Km}^{2}$

\begin{tabular}{|l|c|c|c|c|c|}
\hline \multicolumn{1}{|c|}{ Isla } & $\begin{array}{c}\text { Superficie } \\
1^{\circ} \mathrm{Km}\end{array}$ & $\begin{array}{c}\text { Plazas } \\
\text { turísticas } \\
2015\end{array}$ & $\begin{array}{c}\text { Plazas } / \mathrm{km}^{2} \\
1^{\circ} \mathrm{Km}\end{array}$ & $\begin{array}{c}\text { Residencias } \\
\text { secundarias }\end{array}$ & $\begin{array}{c}\text { Residencias } \\
\text { secundarias } / \mathrm{km}^{2} \\
1^{\circ} \mathrm{Km}\end{array}$ \\
\hline Gran Canaria & 170,11 & 131848 & 775 & 26790 & 157 \\
\hline Mallorca & 362,04 & 279401 & 772 & 54350 & 150 \\
\hline Ibiza & 126,07 & 71883 & 570 & 13000 & 103 \\
\hline Tenerife & 242,47 & 137803 & 568 & 57615 & 238 \\
\hline Lanzarote & 177,04 & 71803 & 406 & 12820 & 72 \\
\hline Menorca & 161,37 & 45407 & 281 & 10395 & 64 \\
\hline Fuerteventura & 242,47 & 61404 & 253 & 3855 & 16 \\
\hline Formentera & 51,92 & 6510 & 125 & 1335 & 26 \\
\hline La Gomera & 73,65 & 5246 & 71 & 3100 & 42 \\
\hline La Palma & 111,33 & 7735 & 69 & 4155 & 37 \\
\hline Hierro & 80,86 & 816 & 10 & 975 & 12 \\
\hline
\end{tabular}

Fuente: INE y portales estadísticos de les Comunidades autónomas

Figura 3. Plazas turísticas (2015) y residencias secundarias (2011) por $\mathrm{km} 21^{\circ} \mathrm{Km}$, en los municipios costeros de Baleares y Canarias

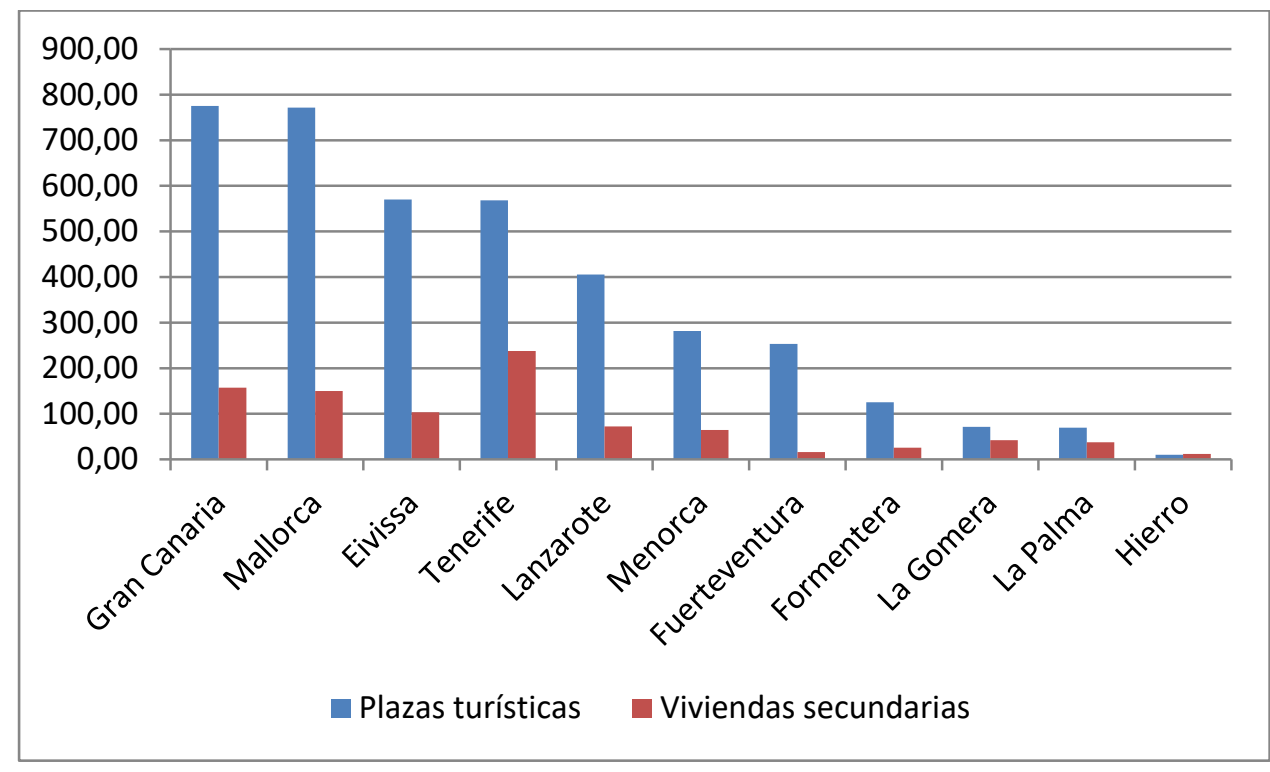

Fuente: INE y portales estadísticos de les Comunidades autónomas 
Figura 4. Plazas turísticas (2015) y residencias secundarias (2011) para los municipios costeros. Costa mediterránea de la península y Baleares

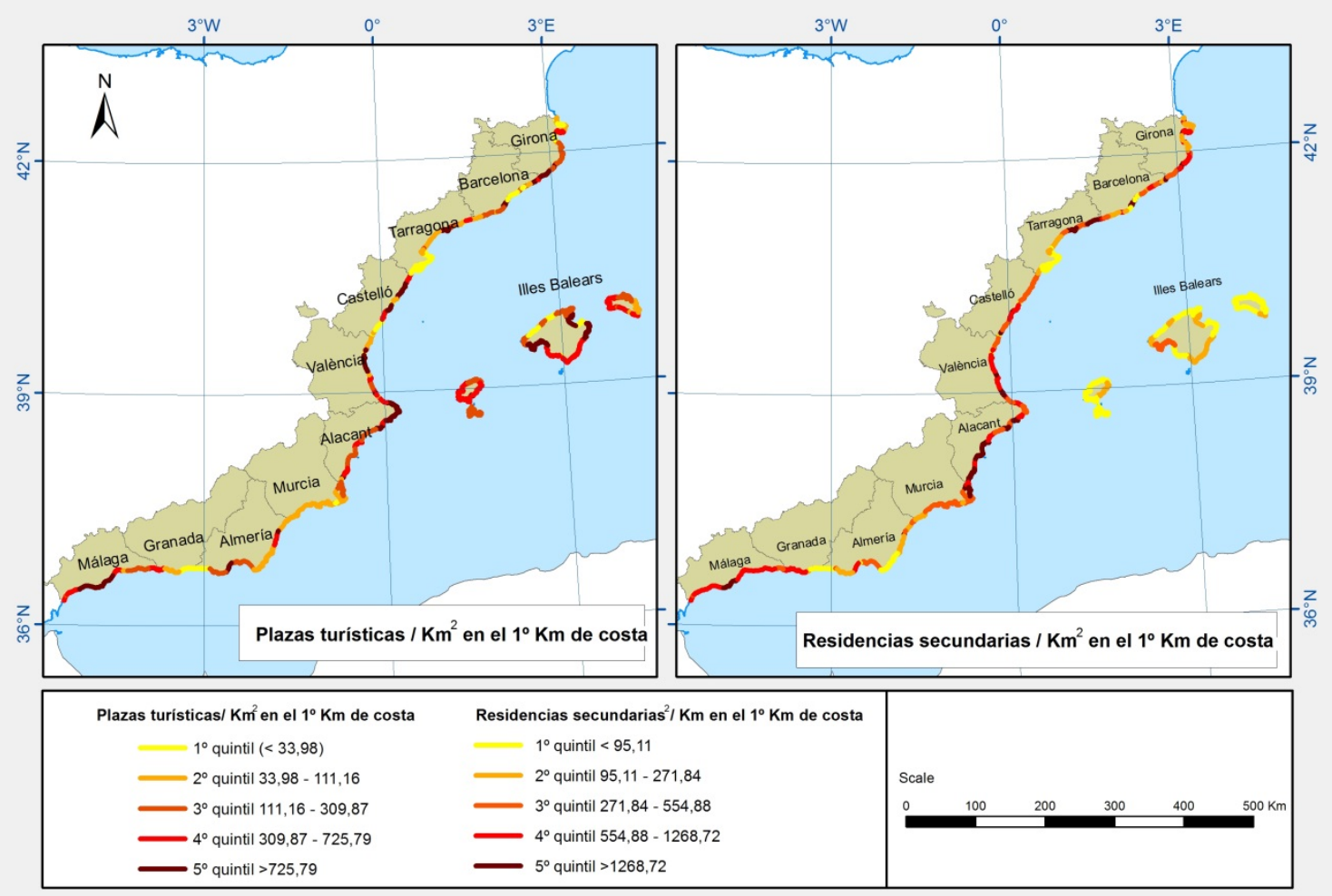

Fuente: INE y portales estadísticos de las Comunidades Autónomas

La evolución de la construcción de residencias secundarias también nos ayuda a confirmar la hipótesis que las regiones insulares presentan una menor intensidad de este tipo de oferta (Figura 5). Por comunidades autónomas se observa como tanto las Islas Baleares como las Canarias han ocupado las últimas posiciones en cuanto a la construcción de residencias secundarias desde mediados del siglo XX. Ciertamente podría haber otros factores que expliquen esta menor presión inmobiliaria, como por ejemplo las políticas urbanísticas y territoriales que se han mostrado más proteccionistas en los archipiélagos desde la década de 1990, pero la posición de los dos archipiélagos en el ranquin, como muestra la Figura 5, se ha mantenido constante con independencia de la implementación de las políticas citadas a partir de la década de los 90 del siglo pasado.

Algunos autores se han hecho eco de la consolidación de procesos de residencialización de las islas en los años de la burbuja inmobiliaria (Simancas \& Mañoso, 2016), tanto por lo que afecta a las Islas Canarias (Muzzi \& Gutiérrez, 2017) como a las Baleares (Blázquez \& Murray, 2010). Efectivamente, en los años previos a la crisis financiera de 2007 se produjo un incremento de los procesos de residencialización en las islas aunque con valores absolutos inferiores a las cifras del 
continente. Si nos centramos en los valores relativos, el crecimiento de residencias secundarias fue importante tanto en Baleares (20\%) como Canarias (24\%) en el periodo 2001-2011, quedando sin embargo por detrás de Murcia (28\%), Comunidad Valenciana (27\%) o Andalucía (26\%).

Figura 5. Evolución de la construcción anual de residencias secundarias

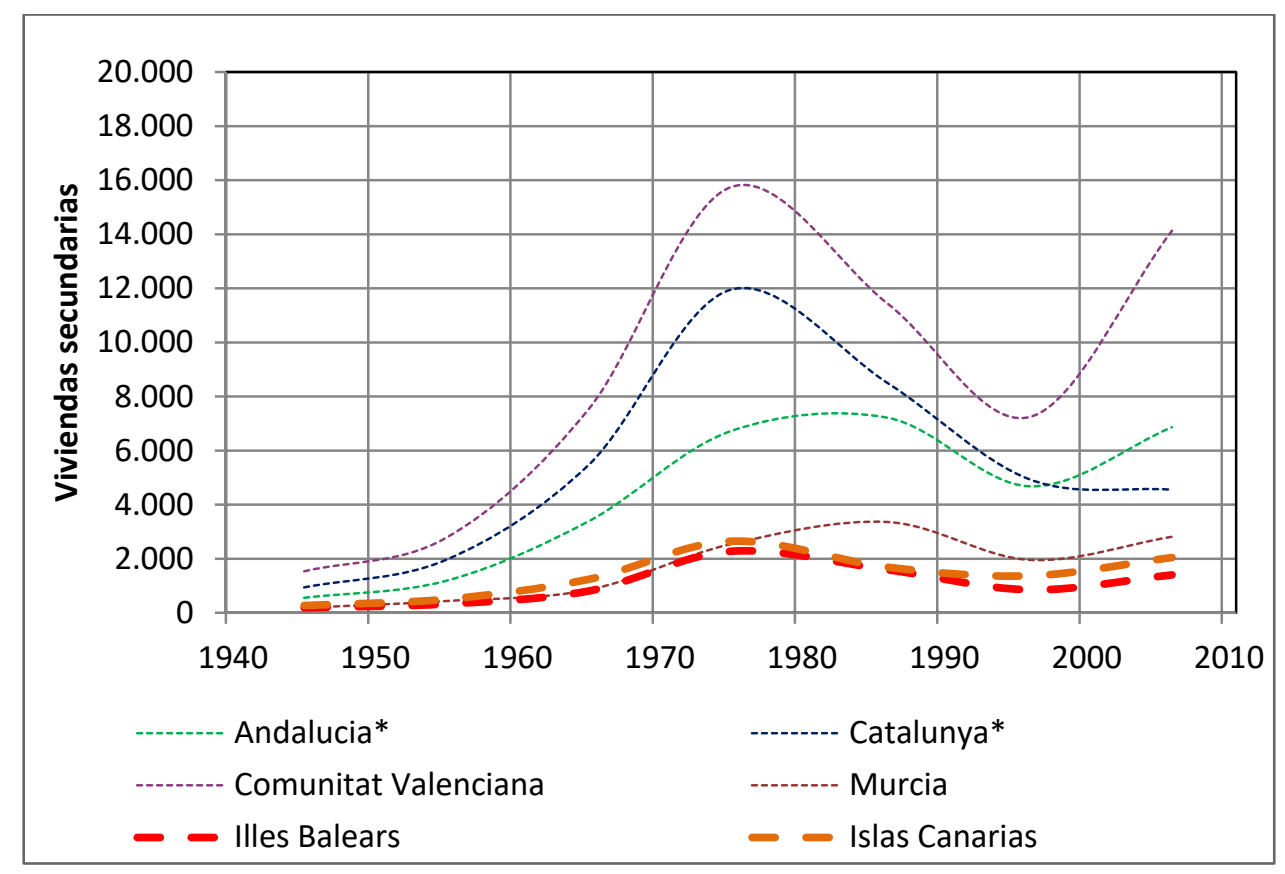

Nota: Datos referidos únicamente a las provincias de la costa mediterránea de la correspondiente Comunidad Autónoma.

Fuente: elaboración propia a partir de Censo de 2011

En resumen, todos los valores apuntan a una diferencia de comportamiento entre las Islas Baleares y la costa mediterránea peninsular. En las Baleares el mayor peso recae en las plazas turísticas, mientras que en la costa peninsular lo hace en las viviendas secundarias. Esta diferencia de comportamiento puede ser principalmente consecuencia de la condición insular (Simancas \& Mañoso , 2016; Fernández \& Barrado, 2011; Pons \& Rullan, 2014). El comportamiento de las dos variables en las Islas Canarias nos ayuda a confirmar la condición insular como un importante condicionante.

La capacidad de atracción de las islas como destinos turísticos (Baldacchino, 2006; Murray, 2012; Wortman, Donaldson \& Van Westen, 2016; Péron, 2004) nos ayuda a explicar gran parte de su mayor peso de plazas turísticas. El "mito de la isla", vinculado a la calma por el modernismo frente a los ajetreados entornos industriales, constituye para muchos autores un factor de atracción primordial de la actividad turística. Además, el turismo es una actividad peculiar porque sus espacios de producción y consumo coinciden, lo cual elimina parte de uno de los inconvenientes que plantea el aislamiento, como son los costes del transporte diario entre los lugares de 
residencia y de consumo (Pons, 2019). Los dos factores indicados combinados han permitido a las islas producir plazas turísticas como mínimo al mismo nivel que el continente.

El interrogante que se nos plantea es el siguiente: si las islas son polos de atracción de la actividad turística, porqué en ellas las viviendas secundarias vinculadas al turismo residencial tienen un peso mucho menor que las plazas turísticas. La magnitud de las islas y la distancia de éstas a las tierras continentales, dos dimensiones ligadas al concepto isleidad (Barceló B. , 1997), pueden ayudarnos a explicar el menor volumen insular de segundas residencias.

La menor extensión territorial, sus recursos más limitados y la dificultad de generar economías de escala han supuesto un freno para la mayoría de actividades insulares, y la urbanización y la producción de segundas residencias son un ejemplo de ello. Asociado a lo anterior cabe resaltar también el menor tamaño de las poblaciones insulares. De hecho las viviendas secundarias están relacionadas con el tamaño de la población, mucho mayor en el continente que en las islas (Pons, 2019).

La distancia a las tierras continentales y la peor conectividad de las islas constituyen otra de sus características que puede contribuir a un menor volumen de potenciales compradores de viviendas. Algunos trabajos se hacen eco de la conectividad como factor explicativo en la expansión de segundas residencias en las islas, como por ejemplo en las islas del Mar Egeo, donde el mayor peso del fenómeno se ha producido principalmente en aquellas más cercanas a Atenas (Kizos, Tsilimigkas \& Karampela, 2017), o por ejemplo con la construcción de un puente de conexión con el continente en la isla de Zhujiajian (China), que ha supuesto una acelerada expansión del área edificada (Xie, Li, Zhang \& Chen, 2018). El acceso por carretera es uno de los factores determinantes en la producción de segundas residencias.

En resumen, a pesar de la capacidad de atracción de las islas como destinos turísticos, los condicionantes vinculados a los desplazamientos entre el lugar de residencia y de ocio del turismo residencial no han permitido evitar los efectos del aislamiento, como sí ocurrió con las plazas turísticas.

La vocación de las islas para la explotación turística rotacional unida a la dificultad, en términos comparativos con la península, para desarrollar una oferta inmobiliaria mayor ha provocado que la comercialización turística a través de plataformas de economía colaborativa -y consecuentemente rotacional- haya proliferado espacialmente en los territorios insulares. En este sentido se entiende el éxito de la comercialización de estancias turísticas en viviendas en las Islas Baleares en forma de alquiler vacacional. El archipiélago se ha convertido en los últimos años en el principal destino 
español de "Airbnb", con 45775 viviendas y 174000 plazas aproximadamente en 2016. El alquiler vacacional de viviendas, en ocasiones llamado genéricamente turismo residencial (Wortman, Donaldson \& Van Westen, 2016) no es nuevo ni en España ni en las islas y, de hecho, muestra más semejanzas con los alojamientos turísticos tradicionales y con el turismo rotacional. El parque inmobiliario de las Baleares, tanto vacío como de primeras y segundas residencias, ha sido rápidamente incorporado al negocio turístico rotacional con nuevas plazas turísticas que se comercializan a través de las llamadas plataformas de economía colaborativa (Yrigoy, 2016). La vocación rotacional del negocio turístico insular ha abonado este tipo de oferta al poner en explotación una parte del parque inmobiliario que no lo estaba hasta la irrupción de este tipo de negocio.

Como consecuencia del mayor peso de la producción económica vinculada directamente a las plazas turísticas, las Islas Baleares son una de las Comunidades Autónomas del Estado donde el turismo tiene un mayor impacto en su economía (Tabla 3). El $44 \%$ del PIB depende directamente del turismo así como el $32 \%$ del total de puestos de trabajo, sólo Canarias, la otra comunidad insular, alcanza cifras similares. ${ }^{7}$ Como se ha apuntado (Rullan, 1998, 2002), el turismo no afecta directamente a la balanza comercial sino a la de pagos, en este sentido, sus productos, las estancias turísticas, no se exportan físicamente sino que se consumen directamente en el destino, la aviación comercial lo ha hecho posible.

Tabla 3. Peso del sector turístico por Comunidades Autónomas

\begin{tabular}{|l|c|c|}
\hline \multicolumn{1}{|c|}{ Comunidad Autónoma } & \% del PIB & \% del empleo \\
\hline Illes Balears & 44,8 & 32,0 \\
\hline Canarias & 31,4 & 35,9 \\
\hline Comunitat Valenciana & 12,6 & 13,4 \\
\hline Andalucía & 12,5 & 11,9 \\
\hline Cantabria & 10,9 & 11,4 \\
\hline Galicia & 10,6 & 11,5 \\
\hline La Rioja & 9,8 & 10,3 \\
\hline Murcia & 9,8 & 10,2 \\
\hline Madrid & 6,3 & 5,9 \\
\hline
\end{tabular}

Fuente: EXCELTUR (2014)

7 Algunos autores como González, Sobral, Hernández y Armengol (2012), apuntan este hecho tomando como ejemplo la isla de Fuerteventura, donde el 70\% del PIB y el 60\% de la población activa viven del turismo de sol y playa. 


\subsection{Sobre el diferente comportamiento insular en la artificialización del suelo}

Es seguramente esta diferencia de comportamiento entre plazas turísticas y viviendas secundarias (figura 4) la que explica fundamentalmente las diferencias de artificialización del suelo de la franja costera peninsular y balear. El fenómeno de las segundas residencias ha fomentado un mayor consumo de suelo, como consecuencia de tipologías urbanísticas y edificatorias unifamiliares y aisladas (Fernández \& Barrado, 2011) mucho más extensivas que las compactas zonas turísticas hoteleras. Son varios los estudios que apuntan a este hecho diferencial entre las Islas Baleares y las regiones costeras peninsulares (Observatorio de la Sostenibilidad en España, 2006; Pons \& Rullan, 2014).

En la figura 6 se detallan, por municipios, los porcentajes de artificialización de la franja costera de $1 \mathrm{Km}$ donde queda mapificado lo que comentábamos en el párrafo anterior. Existe una mayor relación del porcentaje de artificialización de la costa donde predominan las residencias secundarias que donde lo hacen las plazas turísticas. En Baleares sólo los municipios de Palma e Ibiza se encuentran en el quinto quintil con un porcentaje de artificialización superior al 82\%, y en ambos casos el elevado porcentaje de artificialización no se relaciona directamente con residencias secundarias o plazas turísticas, sino que es la función capitalina de las dos ciudades el hecho que lo explica. Sigue en importancia Calvià en el cuarto quintil con un porcentaje artificializado del 55,7\%. En la costa peninsular se encuentran dentro del quinto quintil municipios con una elevada población como es el caso de Barcelona (96\%), Badalona (99\%), Málaga $(79,7 \%)$, pero también municipios con un elevado peso de residencias secundarias como es el caso de Benalmádena (96\%), Torremolinos (93,9\%), Fuengirola $(93,9 \%)$, Orihuela $(90,5 \%)$, Marbella $(89,9 \%)$ o Torrevieja $(71,6 \%)$. 
Figura 6. Porcentaje de artificialización de la franja del primer $\mathrm{Km}$ de costa.

Costa mediterránea de la península y Baleares

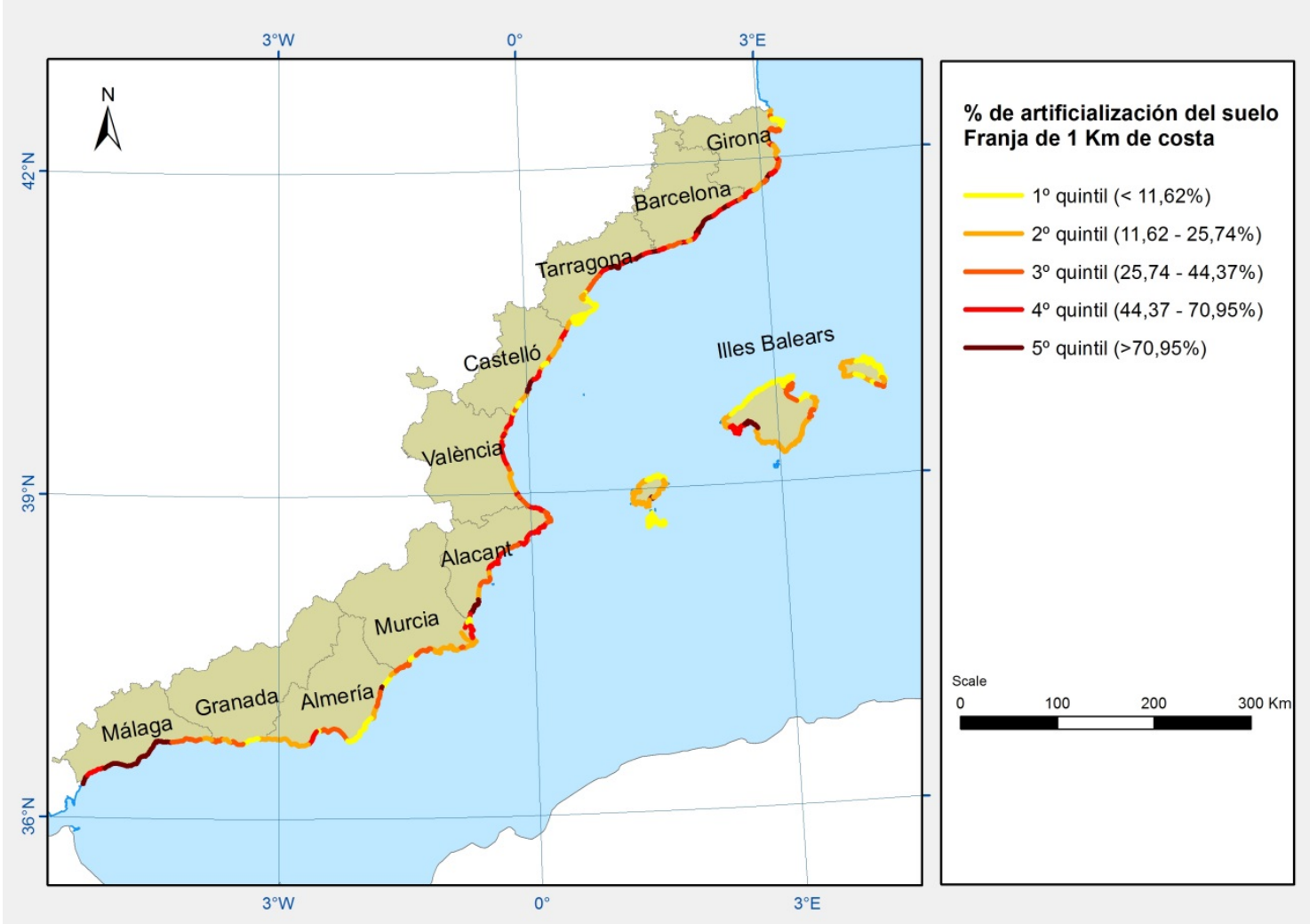

Fuente: Corine Land Cover (2012)

El comportamiento diferenciado de las islas con respecto a las dos estrategias comentadas de producción de espacio turístico (plazas en alojamientos turísticos y segundas residencias) ha implicado diversas consecuencias con respeto al sellado de suelo. En Baleares se ha dado un menor desarrollo del tejido urbano extensivo a la vez que este menor desarrollo de la urbanización extensiva ha supuesto un menor porcentaje de artificialización del suelo (Pons \& Rullan, 2014). Las dos provincias de España con un mayor porcentaje de artificialización del suelo, si exceptuamos Barcelona, son Alicante y Málaga, las dos que tienen una mayor difusión del tejido urbano extensivo vinculado a segundas residencias (Figura 7). Sin embargo, es importante remarcar que en las Islas Baleares el tejido urbano discontinuo, según datos del Corine Land Cover de 2012, representaba el 58\% del suelo artificial de la franja del primer Km de costa. Esta cifra pone en cuestión que existan sólo dos estrategias de producción de suelo turístico (plazas turísticas en tejido intensivo y segundas residencias en tejido extensivo), dado que en Baleares parece evidente que la producción de tejido extensivo debería aplicarse también al vinculado a alojamientos de turismo rotacional. Esta es la estrategia propia del segundo "boom" turístico, en la segunda mitad 
de la década de 1980, con apartamentos turísticos reglados como modalidad de alojamiento característica.

Figura 7. Porcentaje de artificialización del suelo en la franja del primer Km de costa

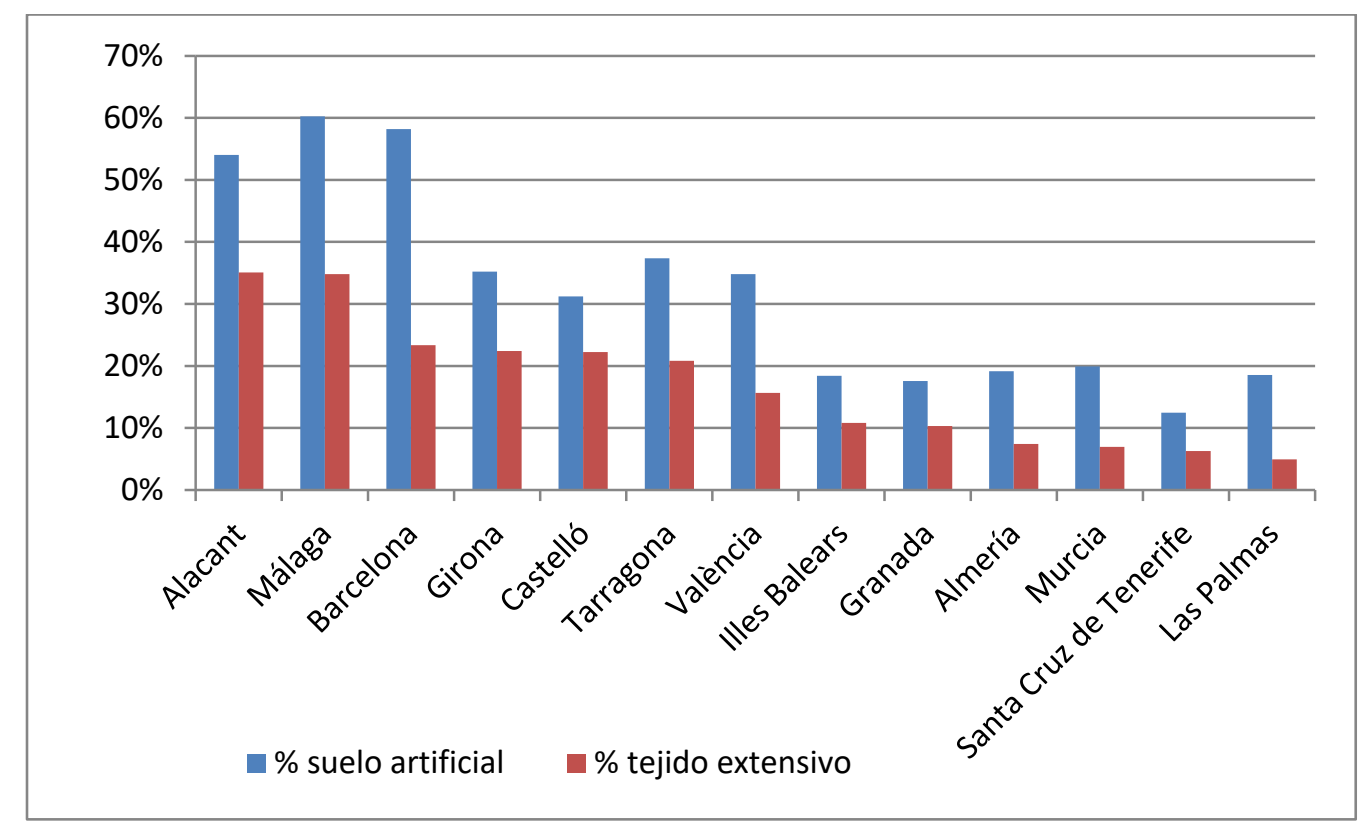

Fuente: Corine Land Cover (2012)

\subsection{Sobre otros posibles factores explicativos}

A parte de la isleidad, y sus factores explicativos (magnitud y conectividad) podría haber otras causas (no alternativas) a la hora de explicar el diferente comportamiento de las Baleares en las variables analizadas. Partiendo del hecho que el contexto internacional es el mismo para las islas y el continente, algunos autores han querido explicar la menor artificialización insular por las medidas de protección derivadas de las políticas territoriales. En esta línea, varios estudios constatan como las islas gozan de mayores porcentajes de territorio protegido. En 1999 era Canarias la primera Comunidad Autónoma de España con superficie protegida (39,97\%), seguida por Baleares (37,45\%). Las dos comunidades insulares eran seguidas, a más de 15 puntos de distancia, por Cataluña (22,02\%) y Andalucía (18,97\%) (González, 2003, p. 145). Pero la argumentación basada en la protección legal de los espacios ha sido contrargumentada por otros autores alegando y constatando que las medidas proteccionistas llegaron cuando ya se daban indicadores claros de menor presión urbanística y artificialización del suelo en comparación con la península (González, Sobral, Hernández \& Armengol, 2012; Pons \& Rullan, 2014), lo cual nos conduce nuevamente a pensar en otras causas como el aislamiento y la condición insular como principales factores explicativos (Pons, 2016) que habrían servido de puente entre la demanda de turismo en islas y la oferta de alojamiento por parte de las empresas turísticas insulares. 


\section{Conclusiones}

Los datos globales del estudio Tabla 4) muestran el efecto diferente de la isleidad, por oposición al continente, sobre la oferta de plazas turísticas y residenciales.

Tabla 4. Plazas turísticas y residenciales en los municipios de la costa mediterránea peninsular españolas y en las islas Baleares. Fuente: elaboración propia

\begin{tabular}{|l|c|c|c|c|}
\hline & Plazas turísticas & $\begin{array}{c}\text { Plazas } \\
\text { turísticas } / \mathrm{Km}^{2}\end{array}$ & $\begin{array}{c}\text { Viviendas } \\
\text { secundarias }\end{array}$ & $\begin{array}{c}\text { Viviendas } \\
\text { secundaria } / \mathrm{Km}^{2}\end{array}$ \\
\hline Islas Baleares & 403445 & 518 & 79080 & 102 \\
\hline Península & 759877 & 504 & 1077520 & 715 \\
\hline
\end{tabular}

Fuente: elaboración propia a partir de INE, Instituto de Estadística y Cartografía de la Junta de Andalucía, Portal estadístico de la Región de Murcia, Portal estadístic de la Generalitat Valenciana, IDESCAT, IBESTAT e ISTAC

Por un lado, la imagen de las islas como paraísos (Martín de la Rosa, 2003) ha impulsado y animado la oferta y la demanda de actividad turística y ha convertido Baleares en uno de los principales destinos del mediterráneo español. Así, en el archipiélago balear se han producido espacios turísticos con plazas en volúmenes equiparables o superiores a las de sus vecinos continentales. En valores absolutos los espacios turísticos de las Baleares acumulan 403445 plazas en establecimientos turísticos reglados en los municipios costeros (2015). Si bien en toda la costa mediterránea peninsular la cifra de plazas turísticas es de 759 877, la cifra balear (superior a más de la mitad de la peninsular) implica una densidad de 518 plazas $/ \mathrm{Km}^{2}$ en la franja del primer kilómetro de costa, supera en 14 puntos a la de la franja litoral mediterránea peninsular (504 plazas $/ \mathrm{Km}^{2}$ ).

Por otro lado, la condición insular ha frenado la producción de espacios urbanizados destinados a la promoción inmobiliaria residencial en términos comparativos con la península. Los costes de producción peninsular, menores que los insulares, el menor tamaño de las promociones insulares y la peor conectividad terrestre con el continente (Fernández \& Barrado, 2011) explica el menor interés empresarial a la hora de invertir en este tipo de oferta. La legislación y planificación territorial balear, más restrictiva que la peninsular (Rullan, 2011), no ha venido más a ratificar un comportamiento diferencial que ya era identificable antes de tales leyes y planes. El menor volumen de potenciales compradores de residencias secundarias derivado de la falta de conexión 
por vía terrestre con la península han sido los mayores factores condicionantes que han impedido generar economías de escala en las islas a los posibles inversores de los excedentes de las actividades económicas peninsulares. El resultado de este freno, que supone esta cara de la isleidad, es el menor volumen de viviendas secundarias y de artificialización del suelo, si se compara con las regiones peninsulares más próximas. En los municipios costeros de las Islas Baleares se censaron 79080 viviendas secundarias $\left(102 \mathrm{vs} / \mathrm{km}^{2}\right)$, cifra muy inferior al de viviendas secundarias de la franja costera continental 1077520 (715 vs/ $\left./ \mathrm{Km}^{2}\right)$. Una densidad que se multiplica por 7 en la península con respeto al archipiélago balear

La isleidad, por tanto, ha condicionado un comportamiento diferenciado de Baleares en relación a las dos estrategias definidas para la ocupación y producción del espacio turístico: los modelos dinámicos de rotación en alojamientos hoteleros ubicados en estructuras urbanas compactas y el modelo turístico residencial asentado en estructuras de ocupación extensiva.

Los datos obtenidos matizan así dos enfoques sobre como la condición insular ha perfilado los procesos turísticos y urbanos: la capacidad de atracción de las islas como destino turístico (Baldacchino, 2006; Murray, 2012; Wortman, Donaldson \& Van Westen, 2016) y la dificultad de las islas para generar economías de escala como consecuencia de su menor conectividad (Bjarnason, 2010; Pintado \& Fernández, 2010; Pons \& Rullan, 2014). A la vista de los resultados del estudio se puede concluir que la isleidad, entendida como condición insular, ha perfilado doblemente la actividad turística en las Islas Baleares.

Agradecimientos: El presente trabajo ha sido posible gracias los proyectos de investigación del Plan Nacional de I+D+l del Ministerio de Economía y Competitividad - FEDER: "Crisis y vulnerabilidad en ciudades insulares españolas: transformaciones en los espacios de reproducción social" (CSO201568738-P) y "El conflicto urbano en los espacios de reproducción. La vivienda como escenario de conflictividad social" (RTI2018-094142-B-C22).

Declaración responsable: Las/os autoras/es declaran que no existe ningún conflicto de interés con relación a la publicación de este artículo. Las tareas se han distribuido de la siguiente manera: el artículo ha sido coordinado de manera conjunta por Onofre Rullan y Antoni Pons. Los dos autores han participado en la revisión bibliográfica y la redacción del artículo. La explotación de los datos y elaboración de la cartografía corrió a cargo de Antoni Pons. 


\section{Bibliografía}

Aguilera-Benavente, F., Botequilha-Leitao, A., \& Díaz-Varela, E. (2014). Detecting multi-scale urban growth patterns and processes in the Algarve region (Southern Portugal). Applied Geography, 53, 234-245. http://dx.doi.org/10.1016/j.apgeog.2014.06.019

Almeida, F., \& Cortés, R. (2011). Transformaciones urbanísticas y territoriales en la Costa del Sol Oriental ¿Otra Costa del Sol Occidental? In Urbanismo expansivo de la utopia a la realidad (pp. 15-28). Universidad de Alicante: XXII Congreso Geógrafos Españoles.

Antón Clavé, S. (1998). La urbanización turística. De la conquista del viaje a la reestructuración de la ciudad turística. Documents d'Anàlisi Geogràfica, 32, 17-43. Retrieved from https://dag.revista.uab.es/

Baldacchino, G. (2004). The coming of age of island studies. Tijdschrift voor Economische en Sociale Geografie, 95(3), 272-283. hitps://doi.org/10.1111/j.1467-9663.2004.00307.x

Baldacchino, G. (2006). Warm versus Cold Water Island Tourism: A Review of Policy Implications. Island Studies Journal, 1(2), 183-200. Retrieved from https://www. islandstudies.ca/

Barceló, B. (1985). Introducció a la nisologia. In I Conferència Econòmica de la Mediterrrània NordOccidental (p. 2071). Barcelona: Fundació del Congrés de Cultura Catalana.

Barceló, B. (1997). Illes, Illeitat i Insularitat. Les Illes Balears, per exemple. Comunicacions de/s membres de la Secció de Filosofia i Ciències Socials XXII. Barcelona: Institut d'Estudis Catalans (pp. 111-127).

Bjarnason, D. (2010). Island Connections: Icelandic Spatiality in the Wake of Worldly Linkages. Island Studies Journal, 5(2), 217-236. Retrieved from https://www. islandstudies.ca/

Blázquez, M. (2006). Eivissa, el paraíso con peor renombre. In Artigues et. al, Introducció a la Geografía Urbana de las Illes Balears (pp. 238-267). Palma: GIST.

Blázquez, M., \& Murray, I. (2010). Una geohistoria de la turistización de las Islas Baleares. El Periplo Sustentable, (18), 69-118. Retrieved from https://rperiplo.uaemex.mx/

Blázquez, M., Murray, I., \& Pons, A. (2008). La explosión turística en las Islas Baleares (19562000). Cambios de usos del suelo y metabolismo socioeconómico. In R. Garrabou, \&J. Naredo, El paisaje en perspectiva histórica: formación y transformación del paisaje en el mundo mediterràneo (pp. 351-375). Zaragoza: Universidad de Zaragoza. 
Butler, R. W. (1980). The concept of a tourist area cycle of evolution: implications for management of resources. Canadian Geographer, 24, 5-13.

Butler, R. W. (1993). Tourism development in small islands: past influences and future directions. In D. G. Lochhart, D. Drakakis-Smith, \& J. A. Schembri, The Development Process in Small Island States (pp. 71-91). London: Routledge.

Cabo, A. (1973). Condicionamientos geográficos. In Historia de España. Madrid: Alfaguara.

Capdepón, M. (2016). Conflictos ambientales derivados de la urbanización turístico-residencial. Un caso aplicado al litoral alicantino. Boletín de la Asociación de Geógrafos Españoles, 71, 3157. http://dx.doi.org/10.21138/bage.2273

Díaz, P. (2015). Pateando el litoral. Barcelona: UPC.

Emmi, P. C., \& Santigosa, M. (1989). Urban development land use planning and political change. The case of Costa Brava, Spain. Land Use Policy 6(2), 103-120. Retrieved from https://www.journals.elsevier.com/land-use-policy

EXCELTUR (2014). Estudio del impacto económico del turismo sobre la economia y el empleo de las Illes Balears. Retrieved from https://www.exceltur.org/impactur/

Ezquerra, A., Moreno, E., Otero, I., \& Urbano, J. (1999). Evaluación de cambios de cobertura del suelo en la Costa Valenciana 1975 - 1991. In VIII Congreso Nacional de Teledetección. Albacete, España, 1999. (pp. 15-18.). Albacete: Santiago Castaño Fernández y Antonio Quintanilla Rodenas.

Femke van Noorloos. (2013). Residential tourism and multiple mobilities: Local citizenship and community fragmentation in Costa Rica. Sustainability, 5(2), 570589. https://doi.org/10.3390/su5020570

Fernández, S., \& Barrado, D. A. (2011). El desarrollo turístico-inmobiliario de la España mediterránea e insular frente a sus referentes internacionales (florida y la costa azul): un análisis comparado. Cuadernos de Turismo, 27, 373-402. Retrieved from https://revistas.um.es/turismo García, F. (2017). Three decades of changes in the world of tourism: the impact of the globalization in the tourist flows. Boletín de la Asociación de Geógrafos Españoles, 75, 127149. http://dx.doi.org/10.21138/bage.2495

García-Ayllón, S. (2015). La Manga case study: Consequences from short-term urban planning in a tourism mass destiny of the Spanish Mediterranean coast. Cities, (43), 141151. http://dx.doi.org/10.1016/j.cities.2014.12.001 
González, A., \& Sobral, S. (2011). El desarrollo urbano-turístico del municipio de Yaiza, Lanzarote: un ejemplo de crecimiento expansivo. In Urbanismo expansivo de la utopía a la realidad (pp. 319-330). XXII Congreso Geógrafos Españoles. Universidad de Alicante.

González, A., Sobral, S., Hernández, J. A., \& Armengol, M. (2012). El desarrollo urbano turístico de Fuerteventura: la búsqueda del desarrollo sostenible versus crecimiento constructivo masivo. Boletín de la Asociación de Geógrafos Españoles, 59, 7-24. http://doi.org/10.21138/bage.1447 González, M. (2003). O territorio protexido nas Comunidades Autónomas. Revista Galega de Economía, 12 (2), 139-158. Retrieved from http://www.usc.es/econo/RGE/Vol\%2012_2/Galego/art6g.pdf

Gormsen, E. (1997). The impact of tourism on coastal areas. Geofournal, 42, 39-54. Retrieved from https://link.springer.com/journal/10708

Harvey, D. (1985) The Urbanization of Capital. Studies on the History and Theory of Capitalist Urbanization. Baltimore: John Hopkins University Press,

Harvey, D. (2007). Espacios del Capital. Madrid: Akal.

Harvey, D. (2012) [2000]. Espacios de esperanza. Madrid: Akal.

Harvey, D. (2014). Diecisiete contradicciones y el fin del capitalismo. Madrid: Traficantes de sueños.

Hepburn, E. (2010). A comparative analysis of island region autonomy. Canadian Political Science Association Conference. Montreal, Québec.

Ibarra, D., Belmonte, F., \& Rubio, J. (2017). The impact of agriculture and tourism on the coast: evolution of change in land use in the watersheds of the region of Murcia (1956-2013). Boletín de la Asociación de Geógrafos Españoles, 73, 295-311. http://dx.doi.org/10.21138/bage.2419

INE (Instituto Nacional de Estadística) (n.d). Retrieved from http://www.ine.es/

Instituto de Estadística y Cartografía (n.d.). Retrieved from http://www.juntadeandalucia.es/institutodeestadisticaycartografia

IBESTAT (n.d.). Retrieved from http://ibestat.caib.es/ibestat/inici

ISTAC (n.d.). Retrieved from http://www.gobiernodecanarias.org/istac/

Institut Estadístic de Catalunya (IDESCAT) (n.d.). Retrieved from http://www.idescat.cat/ 
loannides, D., \& Debbage, K. (1998). The economic geography of the tourist industry: A supply side analysis. London: Routledge.

Jackson, R. E. (2008). Islands on the Edge: Exploring Islandness and Development in Four Australian Case Studies. University of Tasmania. Retrieved from https://eprints.utas.edu.au/7566/

Judd, D. (2003). The infrastructure of play: Building the tourist city. New York: ME Sharpe.

Judd, D. R., \& Fanstein, S. S. (1999). The tourist city. New Haven CT: Yale University Press.

Julbe, F. (1983). Viaje real a un espacio utópico. In F. Julbe, Teoría(s) de Ibiza (pp. 89-100). Ibiza: Libros de la Gorgona.

Kizos, T., Tsilimigkas, G., \& Karampela, S. (2017). What Drives Built-Up Area Expansion on Islands? Using Soil Sealing Indicators to Estimate Built-Up Area Patterns on Aegean Islands, Greece. Tijdschrift voor Economische en Sociale Geografie, 108(6), 836-853.

Lefebvre, H. (1973). La survie du capitalisme. La re-production des rapports de production. Paris: Anthropos.

Marez, I. E. (2012). Movimiento moderno y los proyectos de las estaciones turísticas de Languedoc-Roussillon: La grande-Motte y Port Leucate.Baracrès. Barcelona: UPC. Retrieved from https://www.tdx.cat/handle/10803/128862

Martí Ciriquián, P., Nolasco-Cirugeda, A., \& Serrano-Estrada, I. (2018Land occupation strategies in the Costa Blanca's consolidated tourist areas (Spain). Boletín de la Asociación de Geógrafos Españoles, 76, 430-454. http://doi.org/10.21138/bage.2529

Martí, P., \& Nolasco, A. (2011). La expansión urbanística reciente de la costa alicantina, una realidad constatable. In Urbanismo expansivo de la utopía a la realidad (pp. 367-378). Universidad de Alicante: XXII Congreso de Geógrafos Españoles.

Martín de la Rosa, B. (2003). La imagen turística de las regiones insulares: las islas como paraísos. Cuadernos de Turismo, 11, 127-137. Retrieved from https://revistas.um.es/turismo

Mazón, T., \& Aledo, A. (2005). El dilema del turismo residencial: ¿łurismo o desarrollo inmobiliario? In T. Mazón, \& A. Aledo, Turismo residencial y cambio social: Nuevas perspectectivas teóricas y empíricas (pp. 13-30). Alicante: Aguaclara.

Moles, A A. (1982). Nissonologie ou science des îles. L'espace Géographique, (4), 281289. https://doi.org/10.3406/spgeo.1982.3782 
Mullins, P. (1991). Tourism urbanization. International Journal of Urban and Regional Research, 15(3), 326-342. Retrieved from https://onlinelibrary.wiley.com/journal/14682427

Mullins, P. (2003). The evolution of Australian tourism urbanization. In L. M. Hoffman, S. S. Fainstein, \& D. R. Judd, Cities and visitors: Regulating people, markets and city space (pp. 126142). Oxford: Blackwell Publishing.

Murray, I. (2012). Geografies del capitalisme balear. Poder, metabolisme socioeconòmic i petjada ecològica d'una superpotència turística. Palma: Universitat de les Illes Balears. Retrieved from https://www.tdx.cat/handle/10803/104203

Murray, I., Yrigoy, I., \& Blázquez, M. (2017). The role of crises in the production, destruction and reestructuring of tourist spaces. The case of Balearic Islands. Investigaciones Turísticas, 13, 129. https://doi.org/10.14198/INTURI2017.13.01

Muzzi, G., \& Gutiérrez, J. (2017). La residencialización turística en el sur de Tenerife: el caso del colectivo italiano. Turismo, 6, 63-84. Retrieved from https: //dialnet.unirioja.es/servlet/articulo?codigo $=6480646$

Obiol, E. M., \& Pitarch, M. D. (2011). El litoral turístico valenciano. Intereses y controversias en un territorio tensionado por el residencialismo. Boletín de la Asociación de Geógrafos Españoles, 56, 177-200. Retrieved from https://bage.agegeografia.es/ojs//index.php/bage/article/view/1349/0

Observatorio de la Sostenibilidad en España (OSE) (2006). Cambios de ocupación del suelo en España: implicaciones para la sostenibilidad. Madrid: Mundi Prensa.

Péron, F. (2004). The Contemporary Lure of the Island the Contemporary Lure of the Island. Tijdschrift voor Economische en Sociale Geografie, 95(3), 326339. https://doi.org/10.1111/j.1467-9663.2004.00311.x

Pintado, F. \& Fernández, N. (2010). Insularity in a Community Framework. The status of the Balearic Islands. In C. Manera, \& J. Garau, Insularity in the Mediterranean. Economic and environmental challenges. Madrid: Editorial Pirámide.

Pons, A. (2003). Evolució dels usos del sòl a les Illes Balears. 1956-2000. Territoris, (4), 129145.

Pons, A., \& Rullan, O. (2014). Artificialization and Islandness on the Spanish Tourist Coast. Miscellanea Geographica-Regional Studies on Development, 18(1), 5-

16. https://doi.org/10.2478/mgrsd-2014-0010 
Pons, A., \& Rullan, O. (2014b). The expansion of urbanization in the Balearic Islands (19562006). Journal of Marine and Island Cultures, 3(2), 7888. https://doi.org/10.1016/j.imic.2014.11.004

Pons, A. (2016) Turisme, illeitat i urbanització a les Illes Balears (1956-2006). Palma: Universitat de les Illes Balears.

Pons, A. (2019). Illeïtat, turisme i urbanització a les Illes Balears. Documents d'Anàlisi Geogràfica, 65(2), 321-343. https://doi.org/10.5565/rev/dag.468

Portal estadístic de la Generalitat Valenciana (n.d.). Retrieved from hittp://www.pegv.gva.es/va/

Portal estadístico de la Región de Murcia (n.d.). Retrieved from http://www.econet.carm.es

Qian, J., Feng, D., \& Zhu, H. (2012). Tourism-driven urbanization in China's small town development: A case study of Zhapo Town, 1986-2003. Habitat International, 36, 152160. https://doi.org/10.1016/j.habitatint.2011.06.012

Rico, A. M., Olcina, J., \& Baños, C. J. (2014). Competencias por el uso del agua en la provincia de Alicante: experiencias de gestión en la armonización de usos urbano-turísticos y agrícolas. Documents d'Anàlisi Geogràfica, 60(3), 523-548. https://doi.org/10.5565/rev/dag.136

Royle, S. A. (1989). A human geography of islands. Geography, 74(1), 106-116.

Ruggieri, G. (2011). Tourism in mediterranean islands: a comparative analysis. In J. Carlsen, \& R. Butler, Island tourism. Sustainable perspectives (pp. 186-196). CAB International.

Rullan, O. (1998). De la cova de Canet al tercer boom turístic. In El medi ambient a les Illes Balears. Qui és qui? (pp. 171-213). Palma: Caixa de Balears "Sa Nostra" Obra Social i Cultural.

Rullan, O. (1999). Crecimiento y política territorial en las Islas Baleares (1955-2000). Estudios Geográficos, 236, 403-442. https://doi.org/10.3989/egeogr.1999.i236.570

Rullan, O. (2002). La construcció territorial de Mallorca. Palma: Editorial Moll.

Rullan, O. (2008). Reconversión y crecimiento de las zonas turística. Del fordismo al postfordismo. In Destinos turísticos: viejos problemas, ¿nuevas soluciones? (pp. 587-624). Cuenca: Universidad de Castilla-La Mancha.

Rullan, O. (2011). La regulación del crecimiento urbanístico en el litoral mediterráneo español, Ciudad y Territorio. Estudios Territoriales, 168, 279-297. 
Rullan, O. (2019). Islas globales y paisajes culturales postmodernos en las Islas Baleares. In Paisaxes nacionais no mundo global (pp. 18-43). Santiago de Compostela: Universidade de Santiago de Compostela, Grupo de Análise Territorial (ANTE).

Serrano Martínez, J. (2003). Las viviendas de segunda residencia en la sociedad del "bienestar". El caso de un país turístico: España. Cuadernos de Turismo, 12, 53-75. Retrieved from https://revistas.um.es/turismo

Seto, K. C., Fragkias, M., Günerlap, B., \& Reilly, M. K. (2011). A Meta-Analysis of Global Urban Land Expansion. PLoS ONE, 6(8), 1-9. https://doi.org/10.1371/journal.pone.0023777

Simancas, M., \& Mañoso, J. (2016). La residencialización de las áreas turíisticas de Canarias. $\begin{array}{llll}\text { Promotur turismo } & \text { Canarias } & \text { SA. }\end{array}$ from https://dialnet.unirioja.es/servlet/libro?codigo=674279

Simancas, M., García, J., Dorta, A., \& Falero, R. (2011). El impacto territorial de la moratoria turística de Canarias. In Urbanismo expansivo de la utopia a la realidad (pp. 715-726). Universidad de Alicante. XXII Congreso Geógrafos Españoles.

Sinclair, M. (1998). Tourism and economic development: A survey. The Journal of Development Studies, 34(5), 1-51. https://doi.org/10.1080/00220389808422535

Sufrauj, S. (2011). Islandness and remoteness as resources: Evidence from the tourism performance of Small Remote Island Economies (SRIES). European Journal of Tourism, Hospitality and Recreation, 2(1), 19-41.

Torres, E. (2003). El Turismo residenciado y sus efectos en los destinos turísticos. Estudios Turísticos, (155-156), 45-70. Retrieved from

https://dialnet.unirioja.es/servlet/articulo?codigo $=852412$

UNWTO. (2014). Yearbook of tourism statistics, 2014 edition. Madrid: United Nations World Tourism Organization.

Vera, J. F., \& Baños, C. J. (2010). Renovación y reestructuración de los destinos turísticos consolidados del litoral: las prácticas recreativas. Boletín de la Asociación de Geógrafos Españoles, (53), 329-353. Retrieved from https://bage.agegeografia.es/ojs//index.php/bage/article/view/1204

Villar, A. (2011). Territorio, turismo y paisaje: el proceso de urbanización en el litoral de Andalucía. El papel de los campos de golf (Doctoral dissertation, Universidad de Sevilla, Spain). Retrieved from https://idus.us.es/xmlui/handle/11441/43039 
Wilkinson, P. (1997). Tourism Policy and Planning: Case studies from the Commonweath Caribbean. New York: Cognizant Comunications Corporation.

Wortman, T., Donaldson, R., \& Van Westen, G. (2016). They are stealing my island: Redidents opinions on foreign investment in the residential tourism inustry in Tamarin, Mauritius. Journal of Tropical Geography, 37, 139-157. https://doi.org/10.1111/sjtg. 12151

Xi, J., Zhao, M., Ge, Q., \& Kong, Q. (2014). Changes in land use of a village driven by over 25 years of tourism:The case of Gougezhuang village, China. Land Use Policy, 40, 119130. https://doi.org/10.1016/j.landusepol.2013.11.014

Xie, P., Chandra, V., \& Gu, K. (2013). Morphological changes of coastal tourism: A case study of Denarau Island, Fiji. Tourism Management Perspectives, 5, 7583. https://doi.org/10.1016/j.tmp.2012.09.002

Xie, Z., Li, X., Zhang, Y., \& Chen, S. (2018). Accelerated expansion of built-up area after bridge connection with mainland: A case study of Zhujiajian Island. Ocean and Coastal Management, $152,62-69$

Yrigoy, I. (2016). The impact of Airbnb in the urban arena: towards a toursim-led gentrification. The case-study of Palma old quarter (Mallorca, Spain). In M. Blàzquez, M. Mir-Gual, I. Murray, \& G. X. Pons, Turismo y crisis, turismo colaborativo y ecoturismo (pp. 281-289). Palma: Societat de història natural de les Balears. 